\title{
Characterization of Coal Reservoirs in Two Major Coal Fields in Northern China: Implications for Coalbed Methane Development
}

\author{
Junjia Fan, ${ }^{1,2}$ Yiwen Ju, ${ }^{3}$ Quanlin Hou, ${ }^{3}$ Yudong Wu, ${ }^{4}$ and Xiaoshi $\mathrm{Li}^{3}$ \\ ${ }^{1}$ Research Institute of Petroleum Exploration \& Development, PetroChina, Beijing 100083, China \\ ${ }^{2}$ School of Earth and Space Science, Peking University, Beijing 100871, China \\ ${ }^{3}$ College of Earth Science, Graduate University of Chinese Academy of Sciences, Beijing 100049, China \\ ${ }^{4}$ MLR Key Laboratory of Metallogeny and Mineral Assessment, Institute of Mineral Resources, CAGS, Beijing 100037, China
}

Correspondence should be addressed to Yiwen Ju, juyw03@163.com

Received 12 March 2012; Accepted 2 May 2012

Academic Editor: Hongyuan Zhang

Copyright $\odot 2012$ Junjia Fan et al. This is an open access article distributed under the Creative Commons Attribution License, which permits unrestricted use, distribution, and reproduction in any medium, provided the original work is properly cited.

\begin{abstract}
Based on the macroscopic and microscopic observation of coal structure, the vitrinite reflectance analysis, and the mercury injection testing of coal samples collected from Huaibei coalfield and Qinshui basin, the characterization of coal reservoir and its restriction on the development of coalbed methane are studied. The results indicate that coal reservoir in study area can be classified as five types according to the coal metamorphism and deformation degrees, and they are respectively high grade metamorphic and medium deformational to strongly deformation coal (I), high grade metamorphic and comparatively weakly deformational coal (II), medium grade metamorphic and comparatively strongly deformational coal (III), medium grade metamorphic and comparatively weakly deformational coal (IV), and low grade metamorphic and strongly deformational coal (V). Furthermore, the type II and type IV coal reservoirs are favorable for the development of the coalbed methane because of the well absorptive capability and good permeability. Thus, southern part of Qinshui basin and south-central of Huaibei coal field are potential areas for coalbed methane exploration and development.
\end{abstract}

\section{Introduction}

Coal is not only a kind of mineral fuel but also the reservoir of coalbed methane (CBM). CBM as an unconventional natural gas has gained much attention from researchers around the world. The exploration and development of CBM in America has commercialized over 20 years, and CBM production has industrialized in Australia and Canada in recent years. Based on the successful exploration and development of CBM in USA, the relevant progresses on CBM exploration and development have been summarized during recent years [1-4]. However, because of distinct difference in geological background and coal reservoir characterization, CBM exploration and development in China had not developed successfully as America.

Coal is a kind of porous medium, and its pore structure not only affects gas content but also restricts permeability and recovery of coalbed methane. Currently, scholars have studied pore structure of coals and metamorphic deformational environment by using vitrinite reflectance testing, electronic scanning observation, mercury intrusion testing, low-temperature nitrogen adsorption experiment, nuclear magnetic resonance testing, and CT technology, and they have obtained better understanding on pore structure of coal reservoir, coalbed methane accumulation and recovery $[2$, $5,6]$. However, few scholars combined metamorphism with deformation of coal to discuss pore structure and its restriction on CBM development. In fact, the metamorphism and deformation of coal are affecting coal reservoir property at the same time. Because deformation to some degree can lead to metamorphism, and metamorphism process often accompanied deformation of different degree. Metamorphism and deformation of coal are synthetic processes; they are closely related and mutually interacted. When metamorphism and deformation are allocated reasonably, gas content and permeability of coal reservoir can reach best 

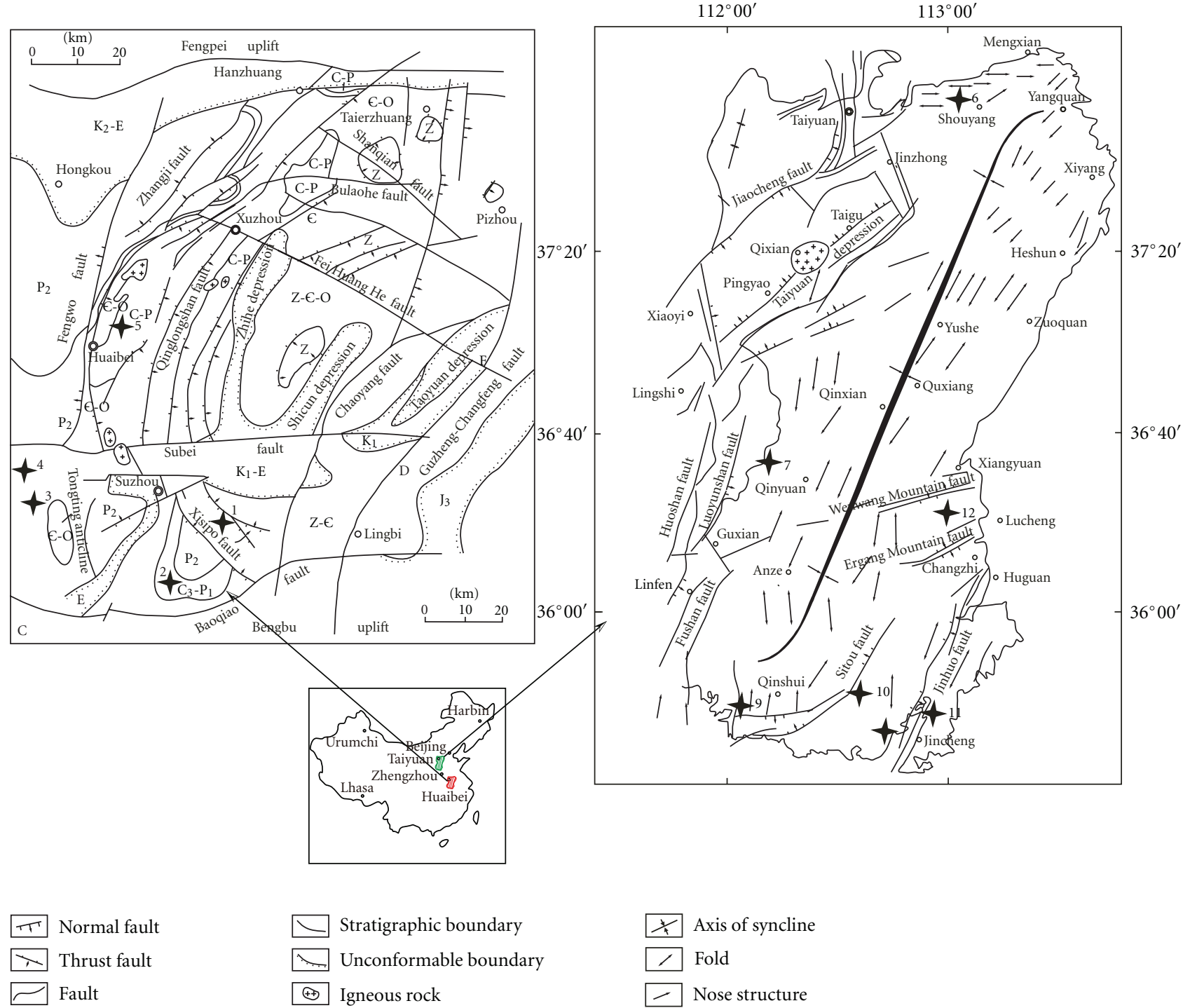

FIGURE 1: Regional geology sketch of Huaibei coalfield and Qinshui basin, and sampling localities (modified from [7-10]) (1) Luling Coalmine; (2) Qinan Coalmine; (3) Linhuan Coalmine; (4) Haizi Coalmine; (5) Shitai Coalmine; (6) Huangdangou; (7) Qinxin Coalmine; (8) Zhangcun Coalmine; (9) Laomufeng Coalmine; (10) Sihe Coalmine; (11) Chengzhuang Coalmine; (12) Wangtaipu Coalmine.

performance and become the favorable coalbed gas reservoir. Better understanding of metamorphism and deformation of coal can get the proper information of coal reservoir, which is of great importance for coalbed methane development. This paper studies metamorphic and deformational characteristics of coal samples collected from Huaibei Coalfield and Qinshui basin and analyzes the pore structures of different coal samples and their restrictions to coalbed methane recovery.

\section{Geological Setting}

Huaibei coalfield and Qinshui basin are typical coal-bearing and coalbed methane-bearing areas in North China. The Huaibei coalfield is located in the northern Anhui province at the southeastern margin of the North China plate sandwiched between W-E direction developed Fengpei uplift and
Bengbu uplift (Figure 1). The Huaibei coalfield is controlled by two groups of faults, one in the EW direction and formed before Carboniferous-Permian and the other in the NNE-NE direction and formed after the coal measure depositional age. The EW-direction faults mainly include the Banqiao fault and Subei fault. The NNE-NE direction faults mainly involve the Zhangji fault, Qinglongshan fault, and Chaoyang fault. These regional faults are located in the southern, northern, eastern, and western parts, respectively. The Xuzhou-Suzhou thrust fault system is another important structure system, which is located in the northeastern area. The coal seams of this area mainly occurred in the folds, especially in synclines. These folds also can be divided into two groups, one group in the NW direction and another in the NNE-NE direction. The NW-striking folds are including the Luling syncline and Tongting anticline, and the NNE-NE striking folds are including the Shuixiao syncline, Zahe syncline, Sunan 
syncline, Sunan anticline, Nanping syncline, Wayang syncline, and Huagu anticline (Figure 1). The Huaibei coalfield has experienced multistage strong tectonic movements and much magmatic activities since the coal depositional age. It is considered that the most important magmatism happened in Yanshanian and the coalfield was greatly altered during this time. There are distinct differences in magmatic activities among its subareas. The magmatism in the north of the Subei fault is stronger than that in the southern part, and the magmatic rocks change gradually from basic rocks in the east, to intermediate rocks in the central area, and to acid rock in the west.

Qinshui basin, which lies in the eastern part of North China, is a synclinorium striking NE-SW direction along Yushe-Qinxian-Qinshui. To the West, the basin edge is defined by Lüliang Mountain, while the eastern part of the basin is bounded by Taihang Mountain which is uplifting area experienced folding-break uplifting since Mesozoic. The area of Qinshui basin is $3.2 \times 104 \mathrm{~km}^{2}$ (about $300 \mathrm{~km}$ in length and $150 \mathrm{~km}$ in width). Compared to surrounding area, tectonics of the Qinshui basin is comparatively weak. The deformation degree weakened from its edge to the inner basin, and in the rim, more thrust faults were developed, which indicates horizontal extrusion. Secondary structures are developed in different area of the basin.

On the whole, tectonic deformation in Huaibei coalfield is comparatively strong, magma hydrothermalism is active, and deformation and metamorphism of coal in this area are intense [11]. Therefore, different coals which indicate the combined effects of tectonism and thermodynamic action are developed. While the Qinshui basin is situated in the transitional area of regional tectonism and deep magma thermology action, where coal reservoir experienced moderate tectonic deformation and distinct magma-thermal action, the metamorphic degree of coal reservoir is strong and the deformational degree is comparatively weak. Consequently, research on the coal samples in these areas is of great significance.

\section{Samples and Analytical Methods}

This research investigates the metamorphism, deformation, and the pore structure systems of coal samples selected from the Huaibei Coalfield and the Qinshui basin by using macro-microscopic observation, vitrinite reflectance $\left(R_{o}\right)$ measurements, mercury intrusion capillary pressure (MICP) testing, and porosimetry. Furthermore, based on tectonically structural coal (TDC) genetic classification [12], systematic classification of coal samples in study area is proposed.

$R_{o}$ measurements (oil immersion) are conducted in Material and Physical Laboratory of the China University of Geoscience (Beijing). Firstly, representative coal samples were polished to coal section and observed by using of oilimmersion objective of MPV-3 microphotometer, and then over 50 points are counted for each sample and calculated the even value as the $R_{o}$ value. Mercury intrusion capillary pressure (MICP) testing was carried out in the Key Laboratory of Natural Gas Development of the Langfang Branch Research Institute, PetroChina. Fresh coal samples were chosen and conducted by MICP test using autopore 9410 porosimeter, its working pressure is $0.0035 \mathrm{MPa}-206.843 \mathrm{MPa}$, resolution is $0.1 \mathrm{~mm}^{3}$, the volume of powder dilatometer is $5.167 \mathrm{~cm}^{3}$, and low limit of pore diameter is $7.2 \mathrm{~nm}$.

\section{Results}

4.1. Metamorphic Characterization of Coal Samples. Metamorphism of coal is a key factor which influences the generation, occurrence, enrichment, and recovery of CBM, and has attracted much attention by scholars for long time [1, 13-15]. Furthermore, deformation of coal also affects porosity of coal and permeability of CBM which restrict effective recovery of CBM; therefore, metamorphism and deformation characterization and their relationship have been the key issue by scholars in recent years $[16,17]$. In order to distinguish effect of metamorphism of coal on CBM and its relationship to CBM enrichment and permeability, researchers classified coal into high-rank, medium-rank, and low-rank coal reservoir according to its metamorphic degree [18-20]. Results of $R_{o}$ measurements show that the $R_{o}$ values in study area varies from $0.78 \%$ to $4.66 \%$. The $R_{o}$ values of coal samples from the Qinshui basin are comparatively high, and the even value is over $1.5 \%$, while $R_{o}$ values of coal samples from the Huaibei Coalfield range from $0.8 \%$ to $3.0 \%$ which indicates coals here have a wide metamorphic range. Based on the previous study $[2,12]$ according to the metamorphism degree, coals in study area are further divided into high-rank coal $\left(R_{o}>2.0 \%\right)$, medium-rank coal $\left(R_{o}=1.3 \%-1.9 \%\right)$ and low-rank coal $\left(R_{o}=0.5 \%-1.2 \%\right)$.

4.2. Deformational Characterization of Coal Samples. Macroscopic observation of representative coal samples shows that the difference of deformation degree is distinct in different areas. It is observed that cataclastic structure coal, mortar structure coal, granulitic structure coal, schistose structure coal, scale structure coal, wrinkle structure coal, and mylonitic structure coal are developed in study area (see Figure 2).

In Huaibei Coalfield, the major coal seams of Haizi Coalmine, Linhuan Coalmine, Luling Coalmine and Qinan Coalmine are no. 8 and no. 9 coal seam of the Lower Shihezi formation of middle Permian and no. 10 coal seams of Shanxi formation of Permian, while the major coal seams in Shitai Coalmine are no. 3 coal seams of Upper Shihezi Formation of Middle Permian. In Qinshui basin, the major coal seams are no. 3 coal seams of Shanxi Formation of lower Permian. Borehole observation of coal seams in coal mines and $R_{o}$ testing of representative samples show that the metamorphic features among different coal samples are obvious. Highly metamorphic and strongly deformational coal seams are featured by wrinkle structure, scaling structure, matrix oriented arranged, and S-C structural fabric; highly metamorphic and comparatively weakly deformational coals are characterized by tension fractures and tension-shear fractures; medium-grade metamorphic and comparatively strongly deformational coals show scaling structure, flowing structure, and S-C structural fabric; tension fracture, shear fracture, and tension-shear fracture are developed 


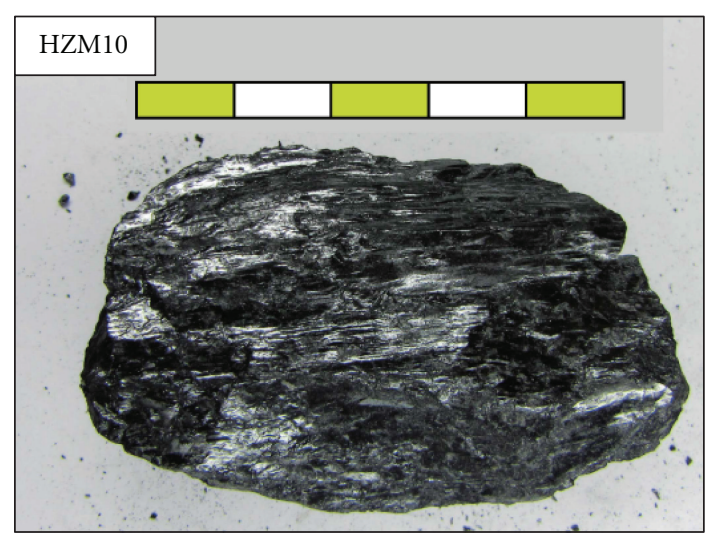

(a)

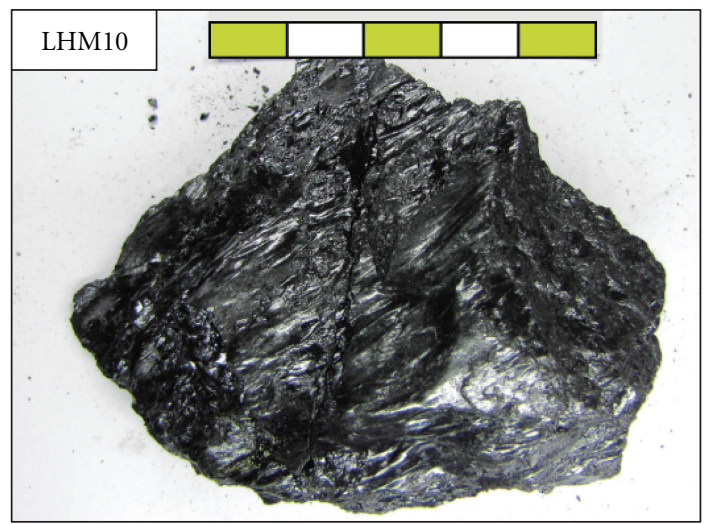

(c)

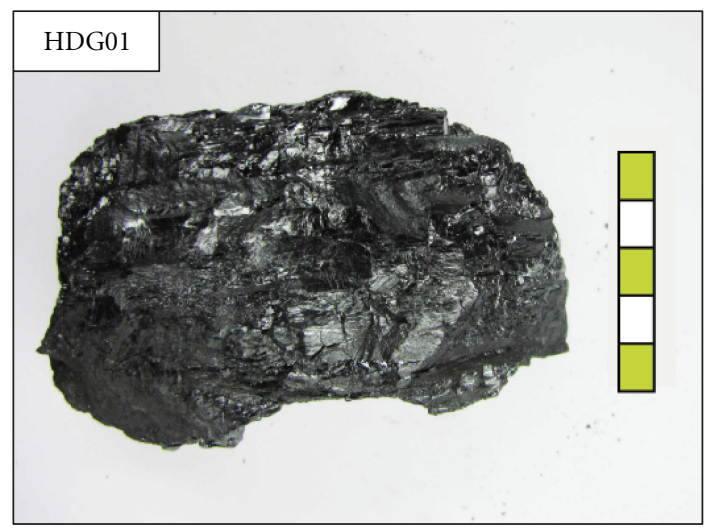

(e)

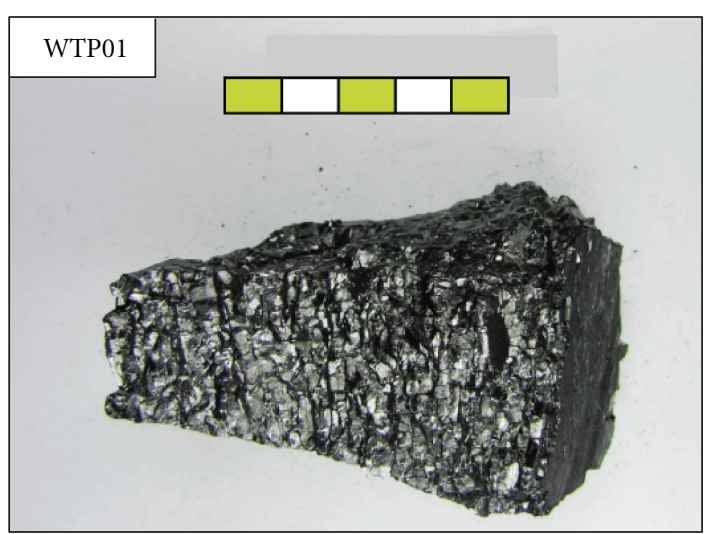

(b)

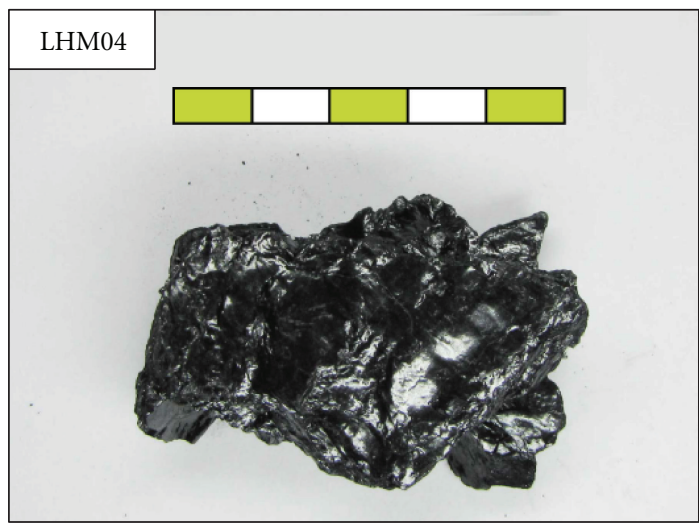

(d)

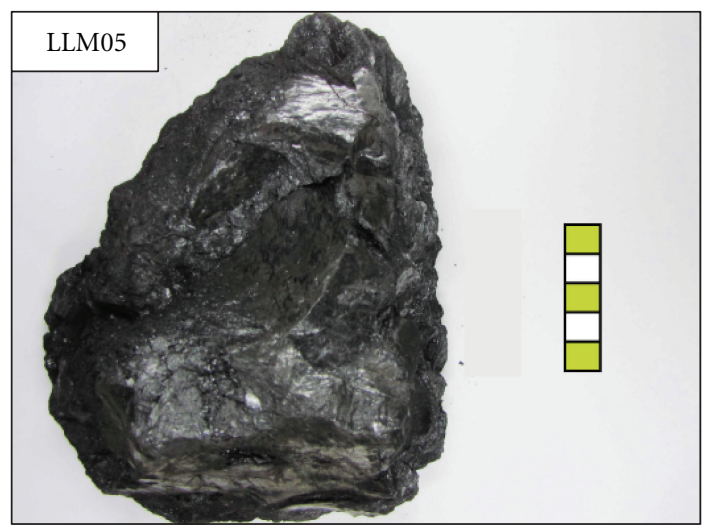

(f)

Figure 2: Photos of different metamorphic and deformational coals.

in medium-grade metamorphic and comparatively weakly deformational coal reservoirs; low-grade metamorphic and strongly deformational coal reservoir are featured by obvious wrinkle structure, flowing structure, and oriented arranged matrix (see details in Table 1).

In Huaibei coalfield, deformation of coal reservoirs is strong, and wrinkle structure coal and mylonitic structure coal are formed universally, while in Qinshui basin, the whole deformation degree for coal reservoir is comparatively weak and cataclastic structure coal and mortar structure coal are formed. According to deformational degree, coal samples are divided into strongly deformational coal, comparatively strongly deformational coal, and comparatively weakly deformational coal (see details in Table 1).

4.3. Pore Structure of Coal Samples. Pores of coal samples are further classified as macropores (diameter $>1000 \mathrm{~nm}$ ), mesopores (diameter $>100 \mathrm{~nm}$ ), transitional pores (diameter $=10-100 \mathrm{~nm})$, and micropores (diameter $<10 \mathrm{~nm}$ ) according to the pore classification proposed by the Former Soviet Union scholars [21]. Gas in macropores and mesopores of coal reservoir existed as laminar flow and 


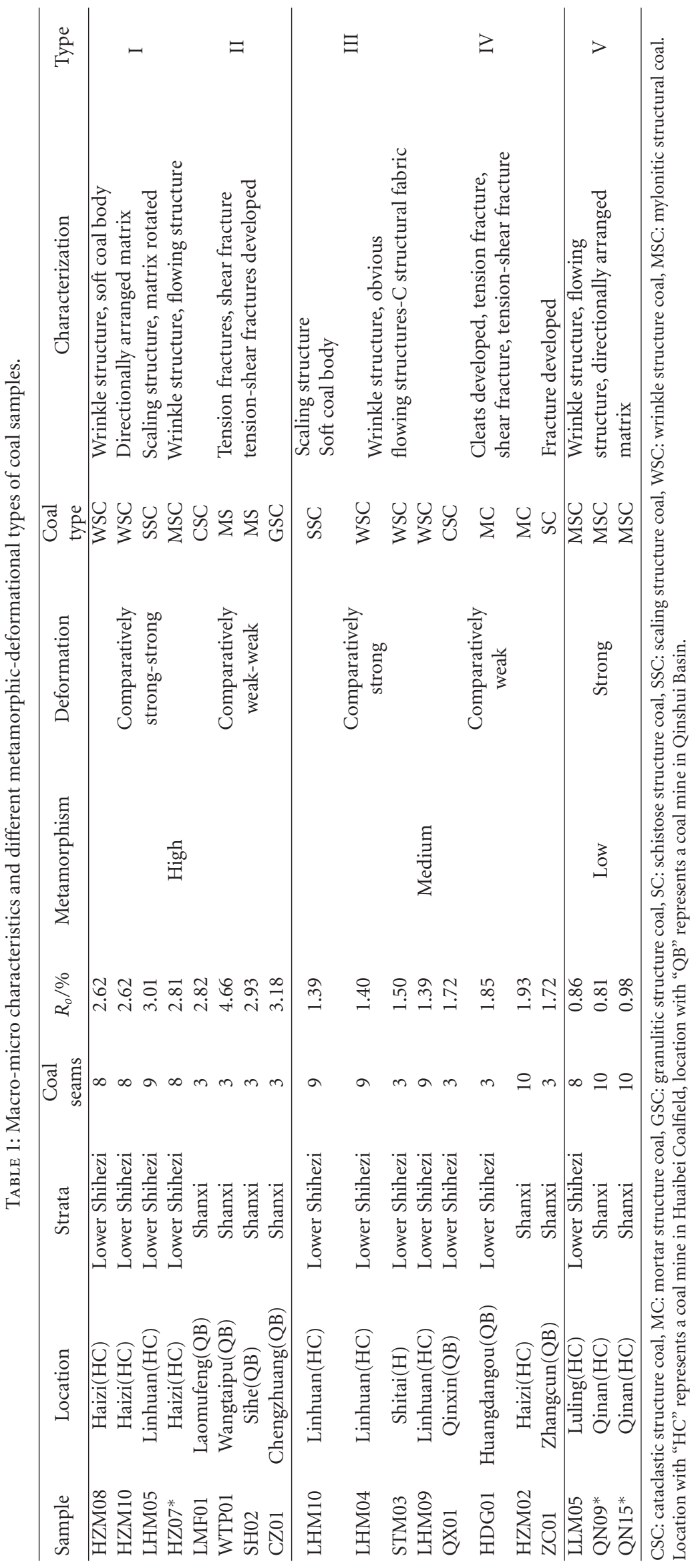


TABLe 2: Analytical results for different metamorphic deformational coal samples by mercury-injecting testing.

\begin{tabular}{|c|c|c|c|c|c|c|c|}
\hline \multirow{2}{*}{ No. } & \multirow{2}{*}{ Sample } & \multirow{2}{*}{ Type } & \multirow{2}{*}{ Mercury ejection efficiency $/ \%$} & \multirow{2}{*}{ Porosity/\% } & \multicolumn{3}{|c|}{ Pore distribution and content } \\
\hline & & & & & $<10^{2} \mathrm{~nm} / \%$ & $10^{2}-10^{3} \mathrm{~nm} / \%$ & $>10^{3} \mathrm{~nm} / \%$ \\
\hline 1 & HZM08 & \multirow{4}{*}{ I } & 38.3 & 9.2 & 76.9 & 14.0 & 9.1 \\
\hline 2 & HZM10 & & 53.9 & 6.9 & 82.8 & 10.2 & 7.0 \\
\hline 3 & LHM05 & & 51.6 & 3.0 & 80.0 & 11.7 & 8.3 \\
\hline 4 & HZ07* & & - & 10.2 & 94.9 & 5.1 & 0 \\
\hline 5 & LMF01 & \multirow{4}{*}{ II } & 68.7 & 2.7 & 78.8 & 7.7 & 13.5 \\
\hline 6 & WTP01 & & 58.0 & 7.2 & 90.0 & 3.5 & 6.5 \\
\hline 7 & SH02 & & 70.0 & 2.5 & 70.5 & 5.9 & 23.6 \\
\hline 8 & CZ01 & & 75.0 & 1.9 & 94.2 & 2.6 & 3.2 \\
\hline 9 & LHM10 & \multirow{4}{*}{ III } & 59.0 & 2.2 & 69.9 & 11.9 & 18.2 \\
\hline 10 & LHM04 & & 44.8 & 2.7 & 72.0 & 11.5 & 16.5 \\
\hline 11 & STM03 & & 52.4 & 2.2 & 55.8 & 2.7 & 30.5 \\
\hline 12 & LHM09 & & 29.9 & 4.9 & 60.5 & 15.5 & 34.0 \\
\hline 13 & QX01 & \multirow{4}{*}{ IV } & 66.5 & 2.7 & 76.3 & 10.2 & 13.5 \\
\hline 14 & HDG01 & & 48.9 & 4.6 & 77.7 & 6.5 & 15.8 \\
\hline 15 & HZM02 & & 49.8 & 2.5 & 69.0 & 13.0 & 18.0 \\
\hline 16 & ZC01 & & 49.9 & 7.1 & 63.6 & 9.6 & 26.8 \\
\hline 17 & LLM05 & \multirow{3}{*}{ V } & 32.6 & 9.0 & 45.6 & 30.7 & 23.7 \\
\hline 18 & QN09* & & - & 4.0 & 40 & 51.9 & 8.1 \\
\hline 19 & QN15* & & - & 3.8 & 54 & 39.4 & 6.6 \\
\hline
\end{tabular}

Note: data with * after Ju [1].

steady-flow form, while gas in micropores of coal reservoir existed as diffusive and adsorbed form. Therefore, pores with diameters larger than $100 \mathrm{~nm}$ are favorable for permeability improvement, while pores with diameters less than $100 \mathrm{~nm}$ are advantageous to CBM adsorption; we named this kind of pores as adsorption pore. Transitional pores and micropores provide main accumulation space for CBM, and macropores mainly affect the desorption and recovery of CBM. See the results of mercury injection testing in Table 2.

\section{Discussion}

Metamorphism and deformation are closely related to the evolution of coal reservoir; different metamorphism of coal may cause different deformation, while the deformation of coal to some extent can bring about metamorphism. Previous research indicates that pore structure, gas adsorption, and permeability varied with coal metamorphism. In addition, coal reservoir property and CBM content changed with coal deformation $[9,15,22]$.

Based on coal borehole and macro-microscopic observation of representative coal samples, coal reservoirs in study area are divided into five types (see Table 1): high-grade metamorphic and medium deformational to strongly deformational coal (I), high-grade metamorphic and comparatively weakly deformational coal (II), medium-grade metamorphic and comparatively strongly deformational coal (III), medium-grade metamorphic and comparatively weakly deformational coal (IV), and low-grade metamorphic and strongly deformational coal (V). Results indicate that porosity and pore structure coal vary with coal metamorphism and deformation.

\subsection{Pore Structure Characterization of Different Metamorphic} and Deformational Coal Reservoirs. Pore structure, pore distribution of different diameters, and pore connectivity are illustrated by using porosimetry and mercury injection testing (see Figure 3 ). Porosity of coal samples varies from $1.9 \%$ to $10.2 \%$ which shows distinct change in different metamorphic and deformational coal reservoirs. The median porosity is between $4.5 \%$ and $5 \%$. For the Type I coal reservoir the mean porosity is $7.3 \%$, the mean porosity of type II coal reservoir is $3.6 \%$, mean porosity of type III coal reservoir is $3.0 \%$, mean porosity type IV coal reservoir is $4.3 \%$, and mean porosity of type $\mathrm{V}$ coal reservoir is $5.6 \%$. Previous research proposed that porosity increased with $R_{o}$ value when $R_{o}$ varied from $0.88 \%$ to $4.6 \%[15,23]$; however, this regulation in our study is not obvious, especially for low-grade metamorphism and strong deformational coal reservoirs which have comparatively high porosity. This can be explained by strongly deformation of coal which changed the pore structures of coal reservoir. For coal reservoir, the porosity of about $7 \%$ is favorable for CBM accumulation and development [24]. Nevertheless, porosity of coal in the study area is low; this is inherent shortage for high-rank coal. Therefore, as far as porosity of coal is concerned, type $\mathrm{I}$ and type $\mathrm{V}$ coal reservoirs are advantageous for CBM development, type II and type IV coal reservoirs are moderate, and type III reservoir is not favorable.

The results of mercury injection testing of representative coal samples show that pore structure changed distinctly 
Sample

number 3
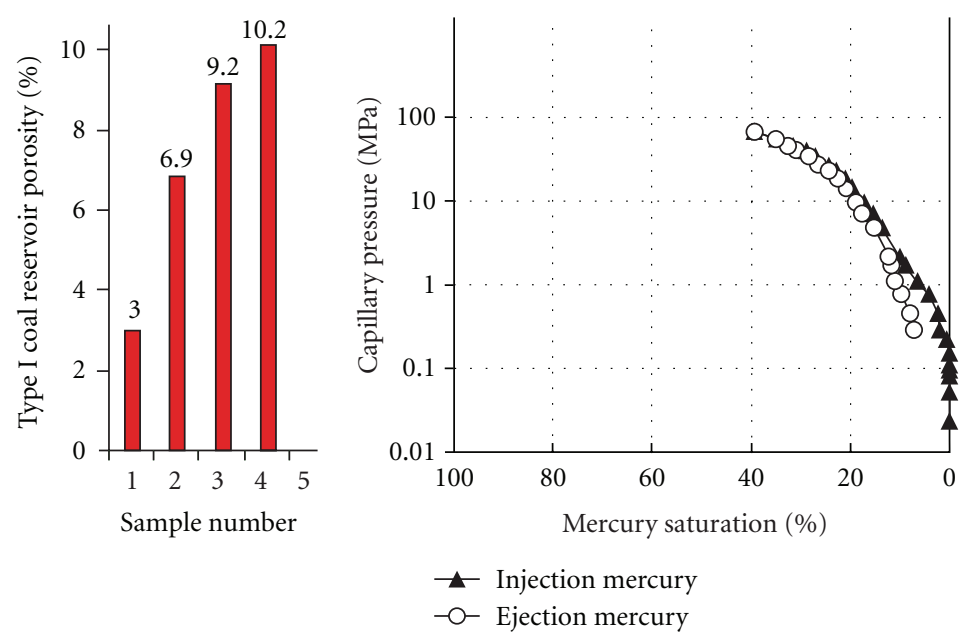

(a) type I coal reservoir Sample number 7
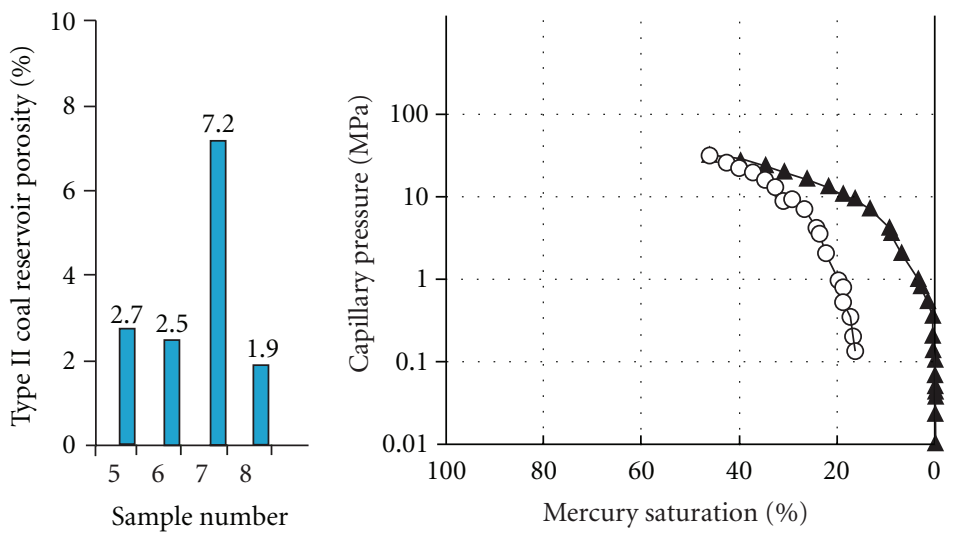

$\neg$ Injection mercury

$-O$ Ejection mercury

(b) type II coal reservoir Sample number 11

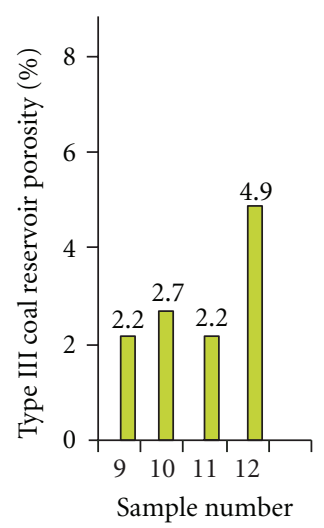

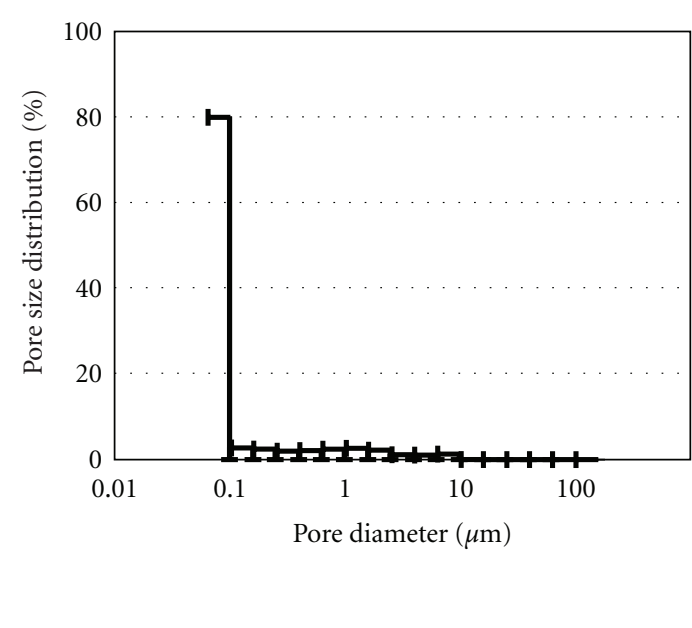

Sample

number 3

Sample

number 7

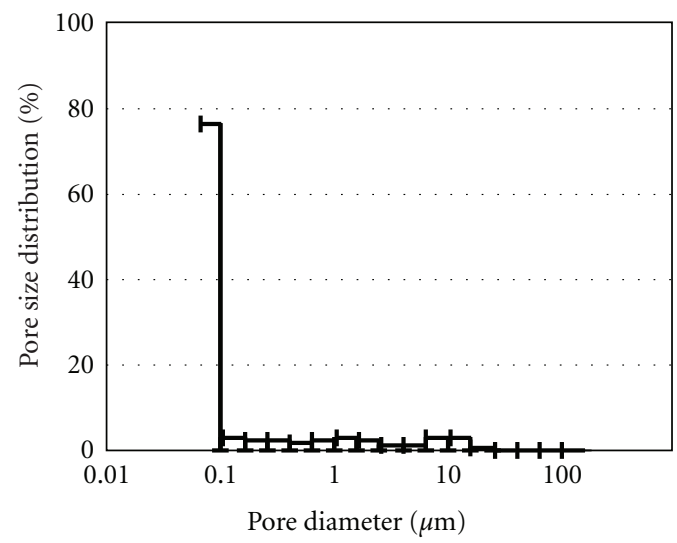

Sample

number 11

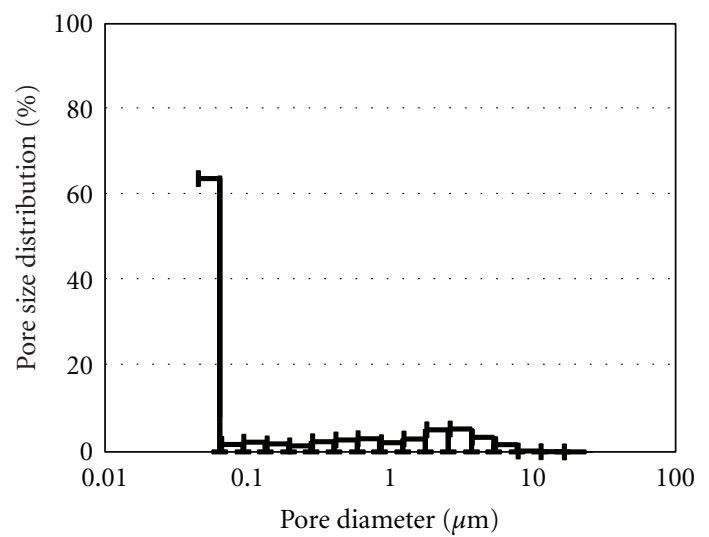

^ Injection mercury

-O- Ejection mercury

(c) type III coal reservoir

Figure 3: Continued. 


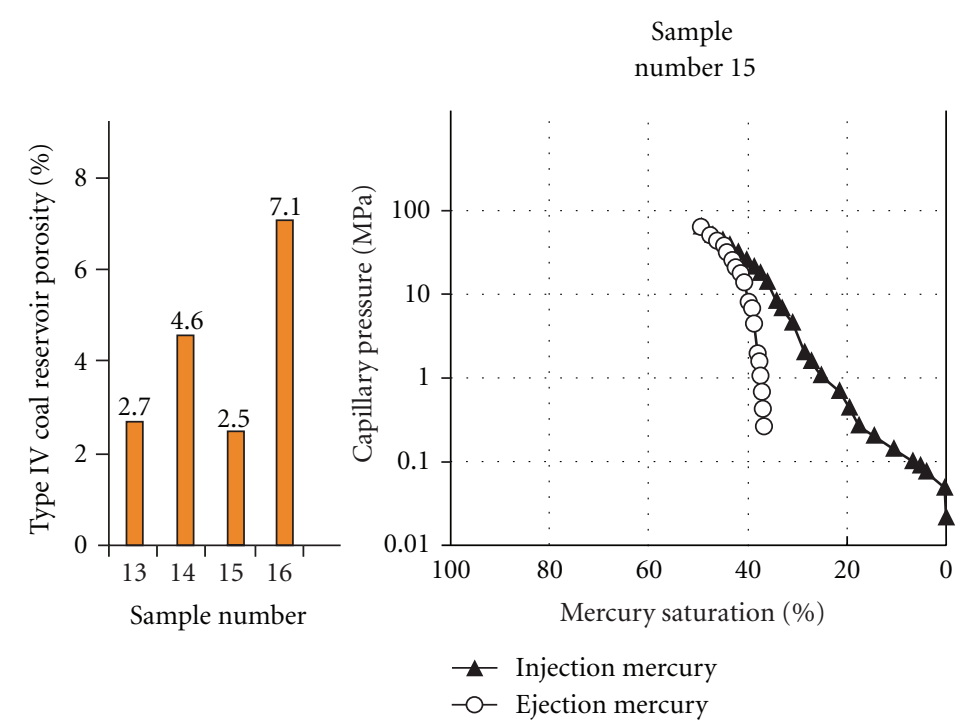

(d) type IV coal reservoir

Sample number 17

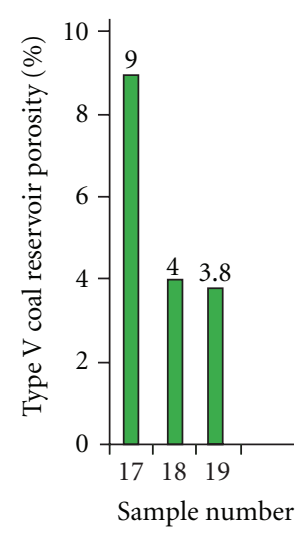

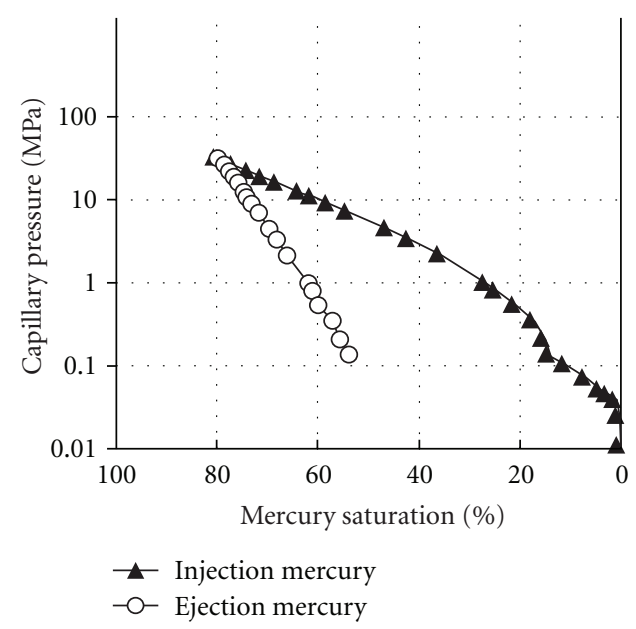

(e) type $\mathrm{V}$ coal reservoir
Sample

number 15

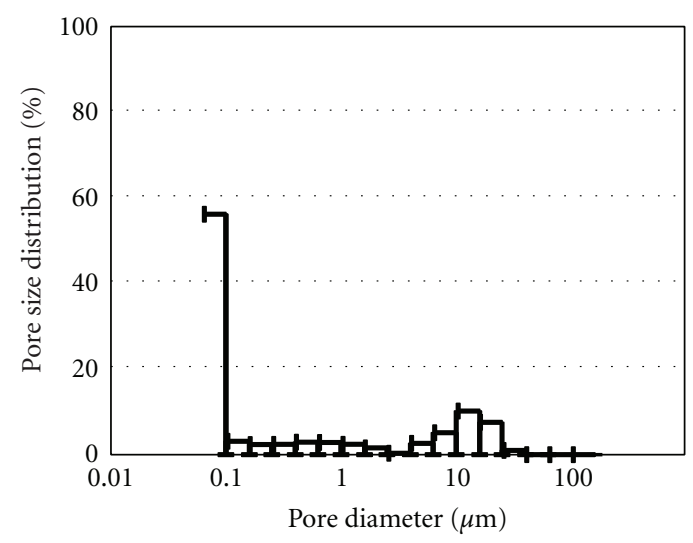

Sample

number 17

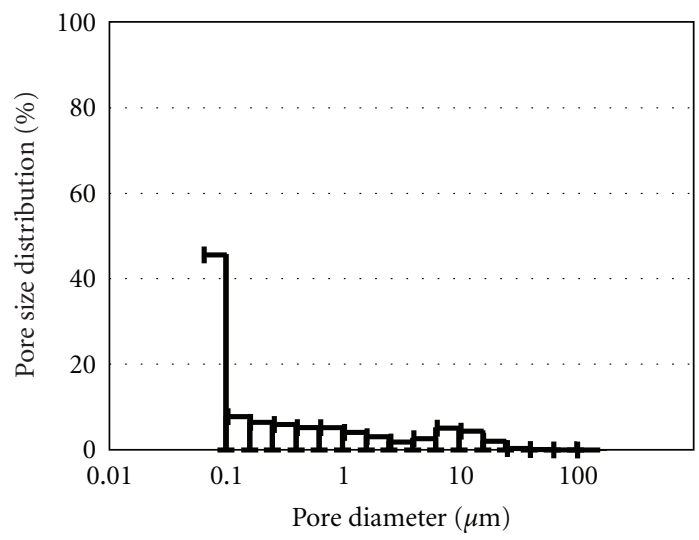

FIGURE 3: Porosity and mercury injection curves of different metamorphic-deformational coals in study area.

with the variation of metamorphism and deformation. The ejection efficiency of coal samples varies from $29.9 \%$ to $75 \%$, and the mean mercury ejection efficiency of type I coal reservoir is $47.9 \%$, mean mercury ejection efficiency of type II coal reservoir is $67.9 \%$, the type III is $46.5 \%$, that of type IV is $53.8 \%$, and that of the last type is $32.6 \%$. Generally, the higher the ejection efficiency, the better the pore connectivity. It is indicated that type II and type IV reservoirs, which have connected pore system and better gas permeability, have better pore connectivity. For high-grade metamorphic coal, micropores are major pores and macropores and mesopores are less. Thus, gas permeability of this type of coal reservoir is generally low. Type I reservoir is characterized by worse pore connectivity and low permeability. While pore connectivity of type II reservoir is better, it has favorable permeability which is resulted from existence of a great deal of fracture generated with deformation of coal reservoir. The mercury ejection efficiency of type III coal reservoir is low, and pore connectivity is worse which may result from strong metamorphism of coal. Mercury ejection efficiency of type IV reservoir is higher, which is contributed by a number of cleats in coal and superimposed fractures generated by deformation. Type V reservoir's pore connectivity is worse which mainly resulted from strong deformation.

On the whole, for type I coal reservoir, the pore content with diameter less than $100 \mathrm{~nm}$ accounts for $80 \%$ and the mercury injection curves and ejection curves show that the pore connectivity is poor. Type II coal reservoir has lower percentage of pore with diameter less than $100 \mathrm{~nm}$, but the pore connectivity is better. Type III coal reservoir, although the percentage of pore with diameter is high $(>100 \mathrm{~nm})$, the pore connectivity is not so good. For type IV coal reservoir, 
percentage of the pore diameter is higher $(>1000 \mathrm{~nm})$ and the pore connectivity is becoming favorable. The last type coal reservoir, with the percent of pore diameter primarily between 100 and $1000 \mathrm{~nm}$, is greater than other types, but the pore connectivity is poor.

\subsection{Pore Structure and Fracture and Their Restrictions to} CBM Recovery. Gas content, permeability, strata pressure, and burial depth are significant parameters for prediction of coalbed methane recovery. However, the metamorphism and deformation of coal and their restrictions on CBM recovery have not gained considerable attention [14]. In general, gas content and permeability are various in different types and brittle deformation can improve gas adsorption content [15]. Nevertheless, strongly deformation will affect the CBM permeability. On the coal metamorphism aspect, gas content increases with metamorphism, which is favorable for CBM accumulation; however, macropore content decreases with the increase of metamorphism, which is disadvantageous for CBM seepage. Exploration and development of CBM proved that CBM recovery is affected by numerous factors. Qinshui basin is located in transitional zone affected by tectonism and deep magma activity. Deformation of coal reservoirs in Qinshui basin is weak, and metamorphics of coal reservoirs are high. Tectonic deformation is strong in Huaibei Coalfield, and magma thermal activity is active; thus, different metamorphic coal reservoirs developed, and their flowing structure, wrinkle structure, is universal.

Affected by tectonism and magma activity, pore structure of different types of coal reservoir is varying. Type I coal reservoir is dominated by adsorption pore, which indicates that this kind of coal has better gas adsorptive capacity. Its ejection mercury curve shows worse pore connectivity, and the permeability is low, which is disadvantageous for CBM desorption. Metamorphic grade of type II reservoir is high, its dominating pores are micropores, and coal reservoir experienced some extent deformation generated numerous fractures; therefore, reservoirs have large gas accumulation space and better permeability, which contribute to CBM development. Gas adsorptive capacity of type III coal reservoir is favorable; however, strong deformation results in decrease of pore connectivity which is unfavorable for CBM seepage. For type IV coal reservoir, numerous cleats in coal and superimposed tectonic fractures contribute to permeability improvement. For type V coal reservoir, although its dominating pores are micropores, the pore connectivity is worse; this is unfavorable for CBM desorption.

In summary, type II coal reservoir has strong gas adsorptive capacity and superimposed some extent structural deformation which generated numerous fractures, and its pore connectivity becomes well, so CBM recovery is good. Type IV coal reservoir has a great deal of cleats, better pore connectivity, and strong gas adsorption capacity; thus, CBM recovery in this kind of reservoir is favorable.

\section{Conclusion}

Based on coal mine investigation of two major coalfields in northern China, combined with macro-microscopic observation and laboratory testing and analysis of representative samples, some conclusions can be drawn as follows.

(I) Coal reservoir in study area can be classified into five types according to the coal metamorphism and deformation degrees, which, respectively, are high-grade metamorphic and medium deformational to strongly deformational coal (I), high-grade metamorphic and comparatively weakly deformational coal (II), medium-grade metamorphic and comparatively strongly deformational coal (III), mediumgrade metamorphic and comparatively weakly deformational coal (IV), and low-grade metamorphic and strongly deformational coal (V).

(II) Pore structure of different metamorphic and deformation coal reservoirs featured by the following characterization: for type I reservoir and type II reservoir, their major pore are micropores; however, type I coal reservoir has poor pore connectivity, and type II coal reservoir has favorable pore connectivity; type III coal reservoir has less micropores compared to type I and type II pore reservoir, and its pore connectivity is worse; therefore, it is not favorable reservoir for CBM development. Type IV coal reservoir has higher micropore content and numerous cleats, and its pore connectivity is better; therefore, it is advantageous for CBM seepage. Type $\mathrm{V}$ coal reservoir has lower micropore contents and comparative mesopore content, but pore connectivity is worse, so it is unfavorable for CBM permeability.

(III) The reservoirs characterized by moderate metamorphism with weak deformation and superimposed tectonic fractures also have strong adsorptive capacity and favorable permeability which are advantageous for the development of CBM.

\section{Acknowledgments}

This work is supported by the National Basic Research Program of China (also called 973 Program) (Grant nos. 2009CB219601), the National Natural Science Foundation of China (Grant nos. 40972131, 41030422, 40772135), National Science and Technology Major Project of China (Grant nos. 2011ZX05060005; 2011ZX05039-004; 2009ZX05039003), and the Strategic Priority Research Program of the Chinese Academy of Sciences (XDA05030100). The authors sincerely thank two anonymous reviewers for their kind comments and useful suggestions.

\section{References}

[1] Y. W. Ju, B. Jiang, G. L. Wang et al., Tectonic Coals: Structures and Physical Properties of Reservoirs, China University of Mining and Technology, Xuzhou, China, 2005.

[2] H. Zhang, X. Y. Li, Q. Hao et al., Study on Scan Electron Microscope of China Coal, Geological Publishing House, Beijing, China, 2003.

[3] Y. Ju, B. Jiang, Q. Hou, and G. Wang, "Relationship between nano-scale deformation of coal structure and metamorphicdeformed environments," Chinese Science Bulletin, vol. 50, no. 16, pp. 1784-1795, 2005.

[4] W. Sun, C. Shi, J. Zhao, and L. Zhao, "Application of X-CT scanned image technique in the research of micro-pore texture 
and percolation mechanism in ultra-permeable oil fieldtaking an example from chang 82 formation in the Xifeng oil field," Acta Geologica Sinica, vol. 80, no. 5, pp. 775-779, 2006.

[5] Y. Ju, B. Jiang, Q. Hou, Y. Tan, G. Wang, and W. Xiao, "Behavior and mechanism of the adsorption/desorption of tectonically deformed coals," Chinese Science Bulletin, vol. 54, no. 1, pp. 88-94, 2009.

[6] J. C. Quick and D. E. Tabet, "Suppressed vitrinite reflectance in the Ferron coalbed gas fairway, central Utah: possible influence of overpressure," International Journal of Coal Geology, vol. 56, no. 1-2, pp. 49-67, 2003.

[7] S. F. Han, Geological Condition and Prediction of Coal Accumulation in Huainan and Huaibei Coalfields, Geological Publishing House, Beijing, China, 1990.

[8] G. L. Wang, D. Y. Cao, and B. Jiang, The Thrust and NappeTectonics and Gravitational Sliding Structure in Southern North China, China University of Mining and Technology, Xuzhou, China, 1992.

[9] Y. Ju, B. Jiang, Q. Hou, G. Wang, and A. Fang, "Structural evolution of nano-scale pores of tectonic coals in southern North China and its mechanism," Acta Geologica Sinica, vol. 79, no. 2, pp. 269-285, 2005.

[10] G. L. Wang, Y. W. Ju, M. L. Zheng et al., Tectonics of Energy Resource Basins in the Northern China, China University of Mining and Technology, Xuzhou, China, 2007.

[11] Y. W. Ju, J.J. Fan, J. Q. Tan et al., "Basin-mountain evolution, lithosphere transformation and their relationship with coalbed methane accumulation in North China," Coal Geology of China, vol. 21, no. 3, pp. 1-5, 2009 (Chinese).

[12] Y. W. Ju, B. Jiang, Q. L. Hou, and G. L. Wang, "New structuregenetic classification system in tectonically deformed coals and its geological significance," Journal of the China Coal Society, vol. 29, no. 5, pp. 513-517, 2004.

[13] R. M. Bustin and C. R. Clarkson, "Geological controls on coalbed methane reservoir capacity and gas content," International Journal of Coal Geology, vol. 38, no. 1-2, pp. 3-26, 1998.

[14] P. H. Zhang, "Key parameters of coal reservior related to coalbed methane recovery of China," Natural Gas Geoscience, vol. 18 , no. 6 , pp. 880-884, 2007 (Chinese).

[15] C. S. Zhu, "The relationship between coal porosity and coal rank," Coal Geology \& Exploration, no. 5, pp. 29-33, 1986 (Chinese).

[16] H. Li and Y. Ogawa, "Pore structure of sheared coals and related coalbed methane," Environmental Geology, vol. 40, no. 11-12, pp. 1455-1461, 2001.

[17] J. Q. Shi, S. Durucan, and I. C. Sinka, "Key parameters controlling coalbed methane cavity well performance," International Journal of Coal Geology, vol. 49, no. 1, pp. 19-31, 2002.

[18] C. Laxminarayana and P. J. Crosdale, "Role of coal type and rank on methane sorption characteristics of Bowen Basin, Australia coals," International Journal of Coal Geology, vol. 40, no. 4, pp. 309-325, 1999.

[19] C. R. Clarkson and R. M. Bustin, "Effect of pore structure and gas pressure upon the transport properties of coal: a laboratory and modeling study. 1 . Isotherms and pore volume distributions," Fuel, vol. 78, no. 11, pp. 1333-1344, 1999.

[20] L. R. Radovic, V. C. Menon, C. A. Leon et al., "On the porous structure of coals: evidence for an interconnected but constricted micropore system and implications for coalbed methane recovery," Adsorption, vol. 3, no. 3, pp. 221-232, 1997.

[21] B. B. Hodot, Coal and Gas Outbursts, China Publishing House of Industry, Beijing, China, 1966, Translated by S. Z. Song, Y. A. Wang.
[22] X. Su, L. Zhang, and X. Lin, "Influence of coal rank on coal adsorption capacity," Natural Gas Industry, vol. 25, no. 1, pp. 19-21, 2005 (Chinese).

[23] Q. L. Zhang, Q. Zhang, H. Zhang et al., "Adsorption characteristics of different rank coals in different area, China," Coal Geology \& Exploration, vol. 2, no. z1, pp. 68-72, 2004 (Chinese).

[24] Y. B. Yao and D. M. Liu, "Developing features of fissure system in Henan coal reserves seams and research on mining of coal bed methane," Coal Science and Technology, vol. 4, no. 3, pp. 64-68, 2006. 

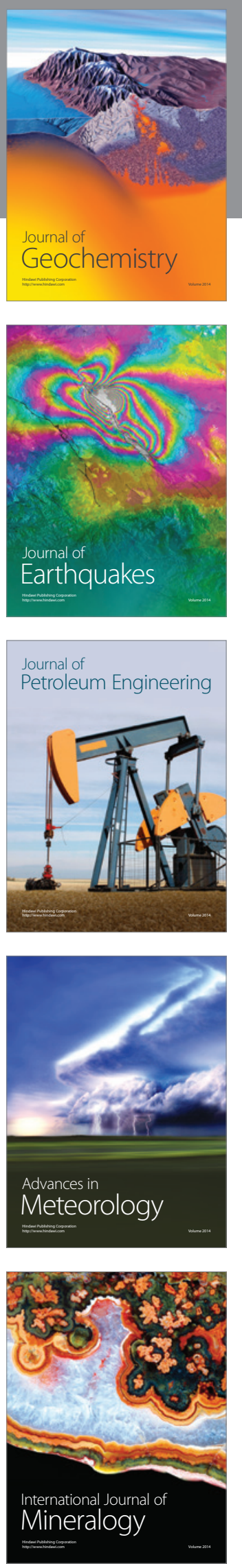
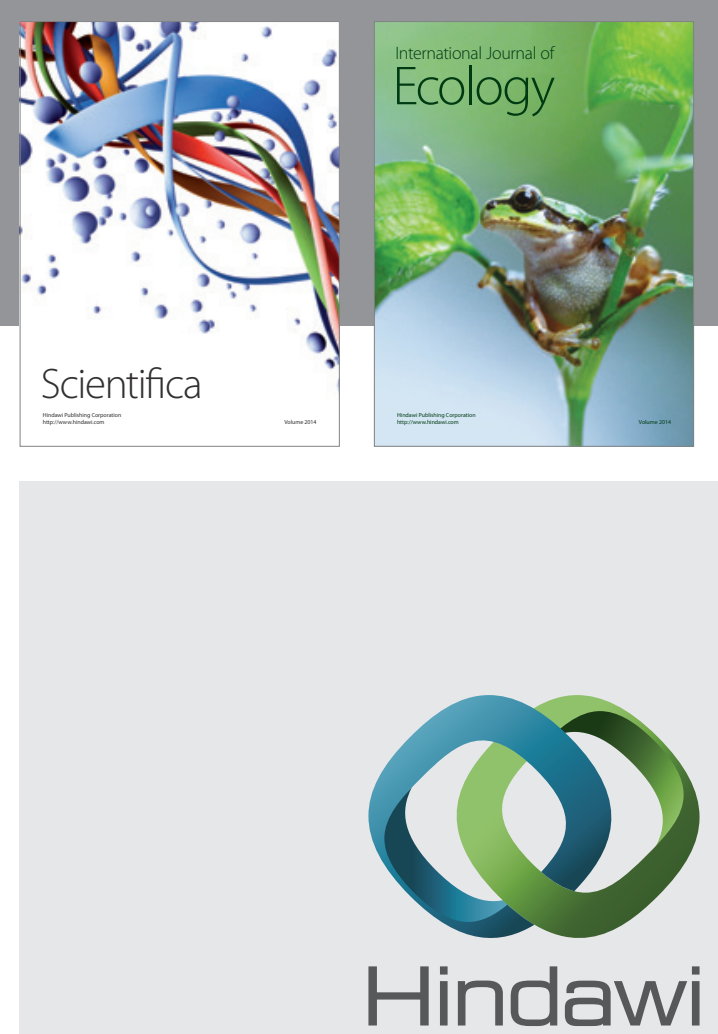

Submit your manuscripts at http://www.hindawi.com
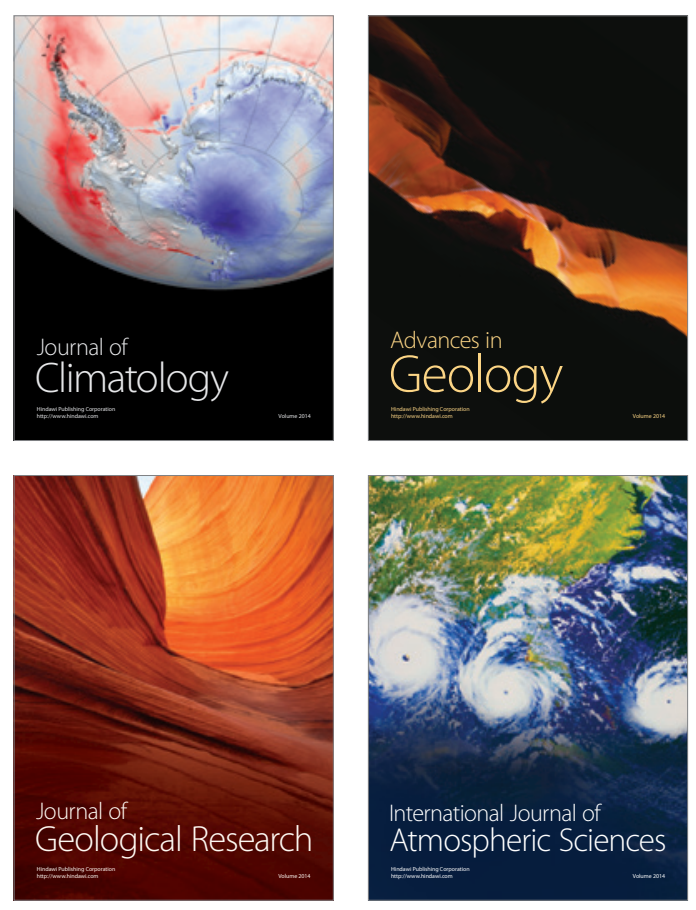
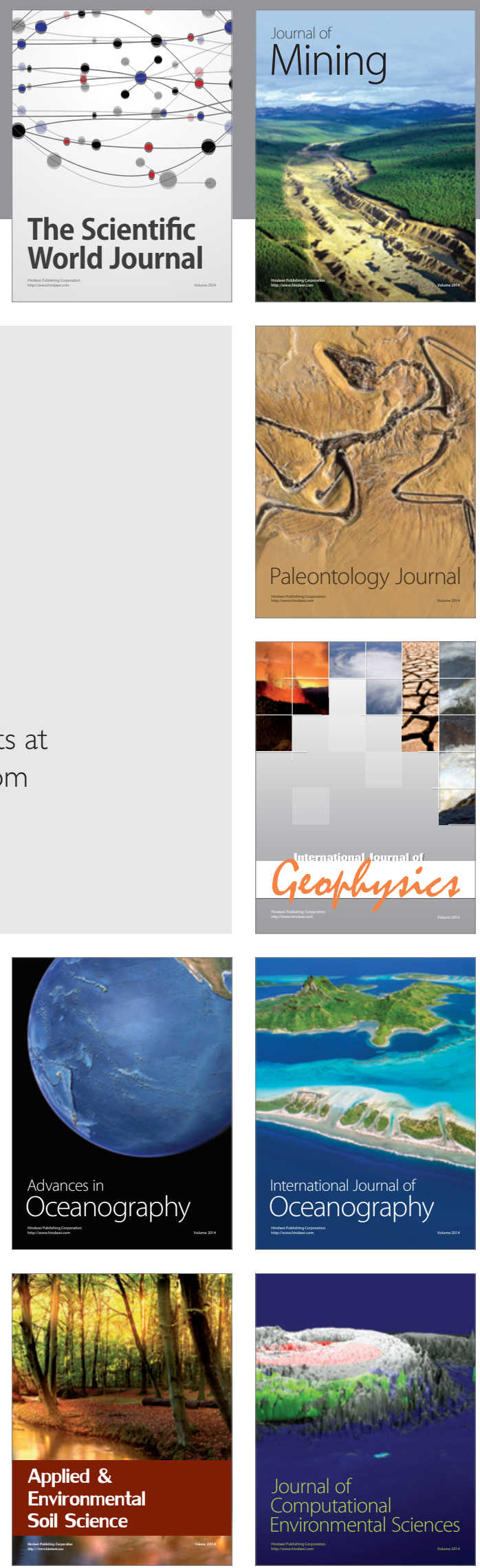